- In the mandible function is more important then aesthetics.

- Interarch space requirements for the different restorations is discussed.

- Long term maintenance must be factored into the cost-benefit of each type of restoration.

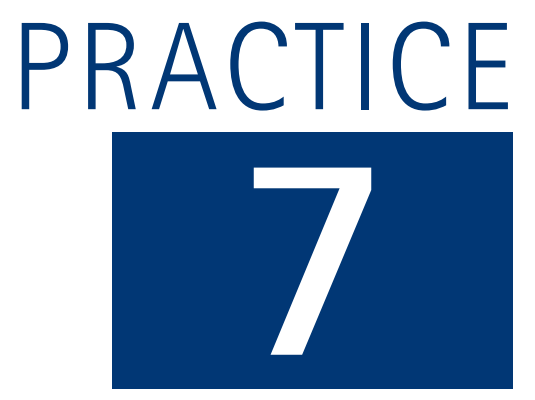

VERIFIABLE CPD PAPER

\title{
Treatment planning of the edentulous mandible
}

\author{
W. Chee ${ }^{1}$ and S. Jivraj ${ }^{2}$
}

Edentulism can be a debilitating handicap. Zarb described endentulous individuals who could not function as 'denture cripples.' Most difficulty with complete denture prostheses arises from the inability to function with the mandibular prostheses. Factors that adversely affect successful use of a complete denture on the mandible include: 1) the mobility of the floor of the mouth, 2) thin mucosa lining the alveolar ridge, 3) reduced support area and 4) the motion of the mandible (Figs 1-2). These factors alone can explain the difficulty of wearing a denture on the mandibular arch compared to the maxillary arch. The maxilla exhibits much less mobility on the borders of the denture than the mandible, moreover having a stable palate with thick fibrous tissues available to support the prostheses and resist occlusal forces. These differences explain most of the reasons why patients experience difficulty with using a complete denture on the mandibular arch compared to the maxillary arch.

\begin{tabular}{|c|}
\hline IMPLANTS \\
\hline 1. Rationale for dental implants \\
\hline $\begin{array}{l}\text { 2. Treatment planning of implants in } \\
\text { posterior quadrants }\end{array}$ \\
\hline $\begin{array}{l}\text { 3. Treatment planning of implants in } \\
\text { the aesthetic zone }\end{array}$ \\
\hline $\begin{array}{l}\text { 4. Surgical guidelines for dental } \\
\text { implant placement }\end{array}$ \\
\hline $\begin{array}{l}\text { 5. Immediate implant placement: } \\
\text { treatment planning and surgical steps } \\
\text { for successful outcomes }\end{array}$ \\
\hline $\begin{array}{l}\text { 6. Treatment planning of the } \\
\text { edentulous maxilla }\end{array}$ \\
\hline $\begin{array}{l}\text { 7. Treatment planning of the } \\
\text { edentulous mandible }\end{array}$ \\
\hline $\begin{array}{l}\text { 8. Impressions techniques for implant } \\
\text { dentistry }\end{array}$ \\
\hline $\begin{array}{l}\text { 9. Screw versus cemented implant } \\
\text { supported restorations }\end{array}$ \\
\hline $\begin{array}{l}\text { 10. Designing abutments for } \\
\text { cement retained implant supported } \\
\text { restorations }\end{array}$ \\
\hline 11. Connecting implants to teeth \\
\hline $\begin{array}{l}\text { 12. Transitioning a patient from teeth } \\
\text { to implants }\end{array}$ \\
\hline $\begin{array}{l}\text { 13. The role of orthodontics in implant } \\
\text { dentistry }\end{array}$ \\
\hline $\begin{array}{l}\text { 14. Interdisciplinary approach to } \\
\text { implant dentistry }\end{array}$ \\
\hline $\begin{array}{l}\text { 15. Factors that affect individual } \\
\text { tooth prognosis and choices in } \\
\text { contemporary treatment planning }\end{array}$ \\
\hline 16. Maintenance and failures \\
\hline
\end{tabular}

\section{INTRODUCTION}

The mandibular denture is a difficult prosthesis to manage. Many articles and techniques have been written about improving the efficacy of the restoration, from differing impression techniques to tooth form. Despite these efforts, there still remain a population of patients who cannot manage using this type of restoration. Presently, some feel that the complete denture prostheses are below the standard of care and that the most basic restoration for the edentulous mandible should be an implant retained overdenture with two implants placed in the anterior mandible. ${ }^{3}$

Treatment choices for the mandible include no treatment, conventional complete dentures, implant supported fixed restorations, implant retained and tissue supported overdentures, implant retained and implant supported

\footnotetext{
1*Ralph W. and Jean L. Bleak Professor of Restorative Dentistry, Director of Implant Dentistry at the University of Southern California School of Dentistry / Private Prosthodontics Practitioner, Pasadena, California; ${ }^{2}$ Chairman, Section of Fixed Prosthodontics and Operative Dentistry, University of Southern California School of Dentistry / Private Prosthodontics Practitioner, Burbank, California;

${ }^{*}$ Correspondence to: Dr Winston Chee, School of Dentistry, Rm. 4374 University Park, University of Southern California, Los Angeles, CA 90089-0641, USA Email:wchee@usc.edu
}

\section{Refereed Paper}

(c) British Dental Journal 2006; 201 : 337-347

DOI: $10.1038 /$ sj.bdj.4814041 overdentures and fixed prostheses with processed acrylic teeth also known as 'hybrid prostheses or bone anchored bridges'. For this article this type of restoration will be termed the hybrid prosthesis and when there is minimal bone resorption, fixed restorations in metal ceramic.

This series of articles attempts to describe the treatment planning aspects of therapy rather than the technical aspects. The discussion will be based on patient needs and desires, anatomical presentation of patients, cost benefit analysis, maintenance and post operative visits.

\section{THE IMPLANT RETAINED AND TISSUE SUPPORTED OVERDENTURE}

This type of restoration is ideal for patients who complain of looseness and mobility of the mandibular denture but not of pain or soreness of the mucosa with use of a mandibular complete denture. The complete overdenture prosthesis is made to full extensions as conventional complete dentures usually are to maximise areas of support for the prosthesis. The function of the implants in this type of restoration is to aid in retention of the prosthesis and not for support of the restoration. Studies have shown that over the long term implants supporting this type of restoration have a high success rate. ${ }^{4-6}$ In its simplest form, two implants are placed between the mental foramina. Due to the function of the genio-glossus muscle and the fact that the mandibular anterior teeth are usually the last 
Fig. 1 Severely resorbed mandibular ridge with genial tubercles extending above the level of the ridge.
Fig. 2 Orthopantomogram illustrating resorption of mandibular arch with inferior dental canal close to the ridge crest and adequate bone to place implants in the anterior mandible.

Fig. 3 Implant retained and tissue supported overdentures have flanges extended for maximum support and stability much as conventional complete denture prostheses have.

Fig. 4 Typical radiographic image of implants placed in the anterior mandible to retain an overdenture prostheses.

Fig. 5 Intra oral image of implant with the healing cap removed.

Fig. 6 Intra oral image of implant in Figure 5 with locator attachment placed - the lowest collar height is selected to expose the retentive element, this lowers the centre of force to the implant and allows more space for bulk of acrylic resin to resist fracture of the overdenture.

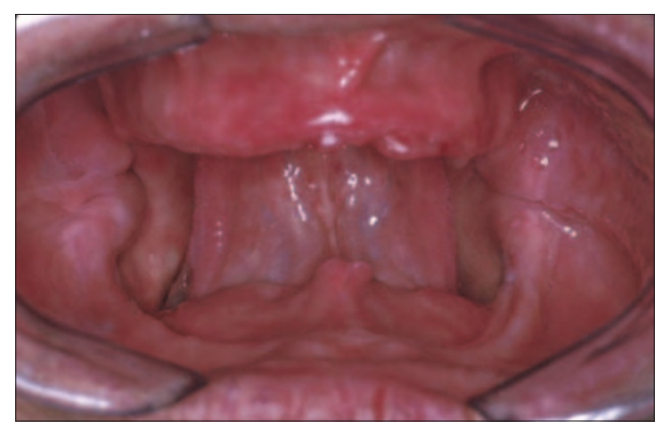

teeth to be lost, there is usually sufficient bone to place implants in this area even though the rest of the alveolus may be severely resorbed (Fig. 4). Unless the implants are very short (8 $\mathrm{mm}$ or less) or they are severely divergent (more than 20 degrees), they need not be splinted. A low profile attachment with easily replaceable retainers should be used (Figs 5-6). At present the most efficacious attachment is the locator attachment manufactured by Zest Attachments, San Diego CA. This attachment is marketed by other implant companies as well eg $3 \mathrm{i}$ (Implant
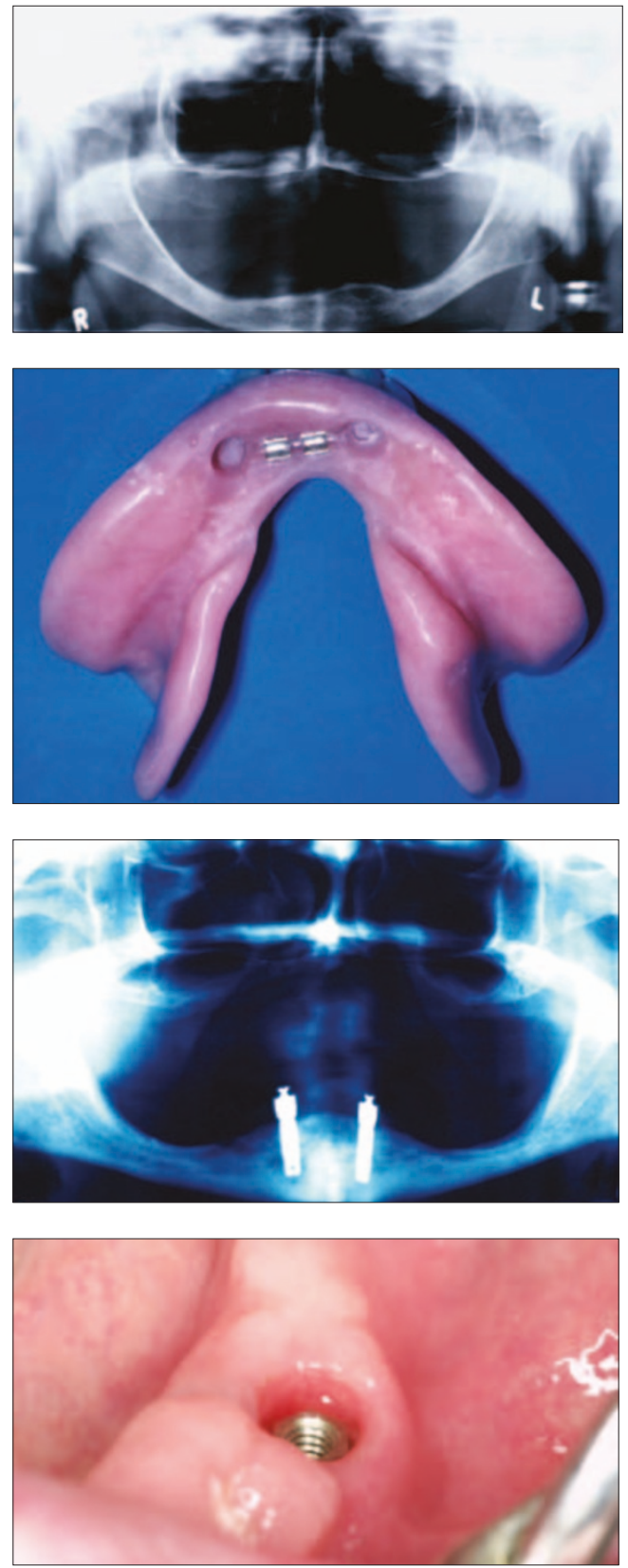
Innovations Inc, Palm Beach, Florida USA). The advantages of this particular attachment are that it is made for many implant systems, it comes in varying heights to accommodate soft tissue thickness, and it has a low profile. The retention can be varied with choice of plastic retentive elements which are easily replaced. One portion of the attachment is screwed directly into the implant body; this is selected to fit the thickness of the mucosa and depth of the implant with the goal to have the implant as low as possible, to expose the retentive element. Advantages of this type of restoration are: 1) reduced number of implants; 2) ability to convert existing removable prosthesis; 3 ) ease of repair of prosthesis.

The disadvantages of this type of restoration are: 1) implants cannot diverge too much; 2) prostheses still require support from mucosa; 3) periodic maintenance is required to replace attachments and to compensate for continued resorption of bone in posterior areas (Figs 7-8).

Adequate inter occlusal space must be present so that a sufficient bulk of acrylic resin can resist fracture; areas where the attachments are will be weakened to accommodate the attachments. $10 \mathrm{~mm}$ of inter occlusal space or more is desirable (Fig. 9). Figures 10 and 11 illustrate a poorly planned overdenture restoration; it is evident that there is insufficient space available for all the implant components. The resulting overdenture will be thin having minimal bulk of acrylic resin resulting in a prosthesis that is weak and prone to breakage.

Since the object of this prosthesis is to be tissue borne, only one axis of rotation should exist for this type of prosthesis. If the prosthesis is not designed to move freely about an axis then premature replacement of the attachments will be required or breakage of components will ensue. With only two implants this objective is achieved automatically (Figs 12-13). Figures 14-16 illustrate a poorly designed overdenture prosthesis. A tissue bar with multiple axes of rotation was fabricated resulting in repeated breaking of the attachments and ultimately breaking of the prosthesis. This occurred due to stresses during function caused by torquing of the prosthesis over the tissue bar. This type of prosthesis is not meant to be fully supported by the implants and some freedom of motion is required to share the load with the mucosa. When implants are too divergent or short and require more implants placed, the prosthesis and tissue bar must be designed to freely rotate 
about one axis. Failure to do so will cause premature wear of components or breakage. ${ }^{7}$

Figures 17-21 show a patient who had four short implants placed in the anterior mandible. A tissue bar was fabricated to splint the implants and distribute the stress amongst them; attachments were placed distal to the posterior implants to create one rotation axis, and the prosthesis was relieved to rotate freely about this axis. Figure 21 demonstrates the stability of the implant retained overdenture, the prosthesis remains stable though the tongue is protruded.

Though costs of implant retained overdentures are increased over conventional complete dentures, when this service is provided there is growing evidence that patients who receive this type of prosthesis benefit with better function, nutrition and general well being. ${ }^{8-15}$ An important issue with this type of restoration is that patients must be informed that they will still have a removable prosthesis, the mucosa below the denture bases will still be loaded and continued maintenance of the prosthesis once delivered will be required. The maintenance will include regular relines of the prosthesis, regular replacement of attachments, good oral hygiene and prophylaxis of the implants and possible breakage of components. ${ }^{16-21}$ Patients must be informed of these facts prior to beginning treatment; adjustments are most frequent during the first year of usage and will continue. Another consideration of providing this type of restoration is to consider the effect on the maxillary arch. It has been shown that there is increased resorption of the anterior maxilla and mandibular posterior ridges with long term use of the implant retained overdenture. This could be due to the increased bite forces generated directly over the implants in the anterior mandible. Regular relines are indicated to maintain an even contact between the maxillary and mandibular prostheses.

There are also reports in the literature about immediately loading implants with overdentures. Though this is possible, caution should be taken with patient selection and mode of restoration. Most of the studies with overdenture restorations immediately loaded have the implants splinted with a tissue bar. This increases the cost of the procedure and makes maintenance more difficult. ${ }^{26,27}$

\section{THE HYBRID RESTORATION}

When the anatomical presentation of the patient will allow an overdenture restoration and more than two implants are possible, the choice of restoration to be placed should be the implant supported fixed restoration or hybrid type restoration. The implant retained and supported overdenture has little indication in the mandibular arch when four or more implants are placed. The hybrid restoration requires that four to six implants are placed between the mental foramina. These implants are sufficient to support a fixed restoration with cantilevers posterior to the terminal implants (Figs 22-23).

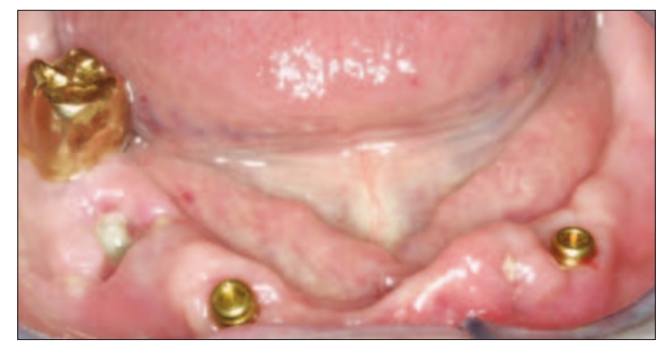

Fig. 7 Intra oral view of two attachments placed to retain overdenture - note that they are spaced to allow more implants to be placed should the patient decide to have a hybrid restoration in the future.

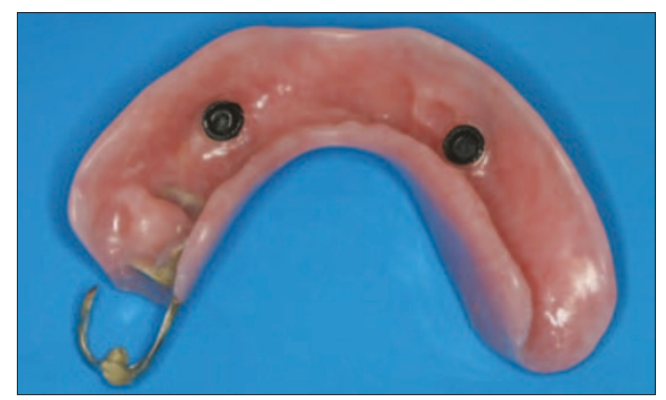

Fig. 8 Prosthesis for patient in Figure 7 with attachment blanks picked up, these blanks can be changed for attachments with varying amounts of retention.

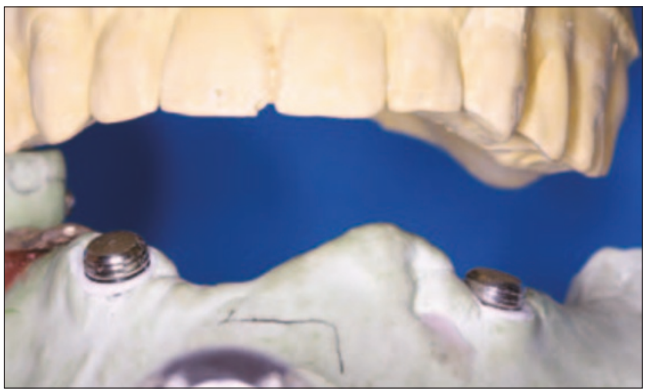

Fig. 9 Casts should always be mounted in the diagnostic phase to ensure that sufficient interocclusal space is available.

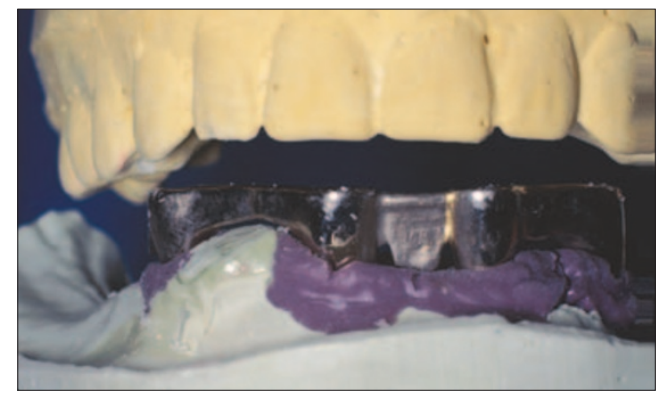

Fig. 10 Mounted casts indicating insufficient room for the implant components and the tissue bar.

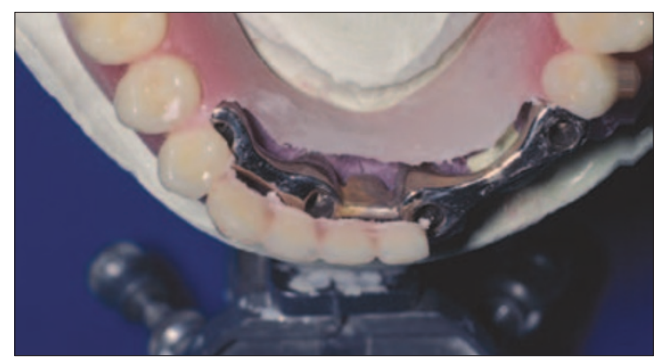

Fig. 11 Occlusal view of casts showing minimal space for the overdenture prosthesis components over the tissue bar.

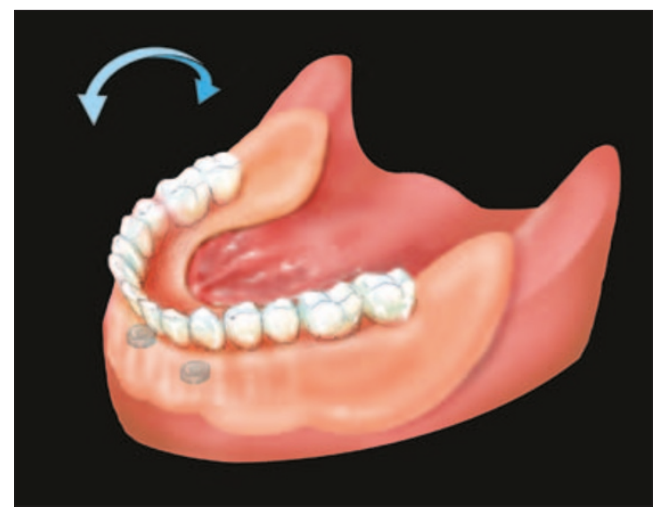

Fig. 12 When there is one axis of rotation the prosthesis can freely move and share the load with the mucosa. The implants serve to retain the prosthesis. 
Fig. 13 When there is no axis of rotation the prosthesis will bind and torque the tissue bar and implants which leads to failure of the components.

Fig. 14 Intra oral view of poorly designed tissue bar.

Fig. 15 Broken attachment clip from prosthesis over tissue bar in Figure 14.

Fig. 16 Broken prosthesis constructed over tissue bar in Figure 14.

Fig. 17 Radiograph of severely resorbed mandible with fractures on left and right side, inferior dental nerve has been severed bilaterally and the patient has difficulty using a conventional prosthesis, four short implants are inserted in the anterior mandible.

Fig. 18 Tissue bar constructed for patient in Figure 15 - to maintain only one axis of rotation in order that the prosthesis has freedom of rotation the attachments are placed distal to the last implant.

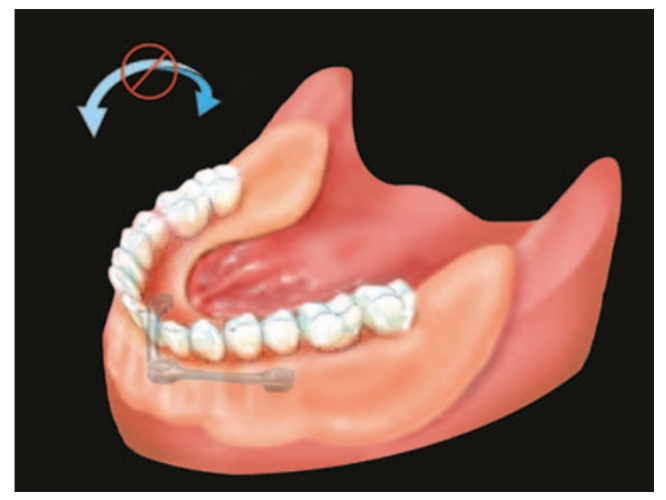

This type of restoration is dependent totally on the implants for support and can be provided for all edentulous patients who have sufficient bone and inter arch space to receive implants in the anterior mandible. With age changes and the many medications that reduce saliva flow, removable prostheses are extremely uncomfortable for xerostomic patients to wear. Since the hybrid prosthesis does not load the mucosa, patients who experience pain when using conventional complete denture prostheses are well suited to this type of restoration (Fig. 24). In addition the hybrid type restoration has the most documentation over a long term. ${ }^{28,29}$

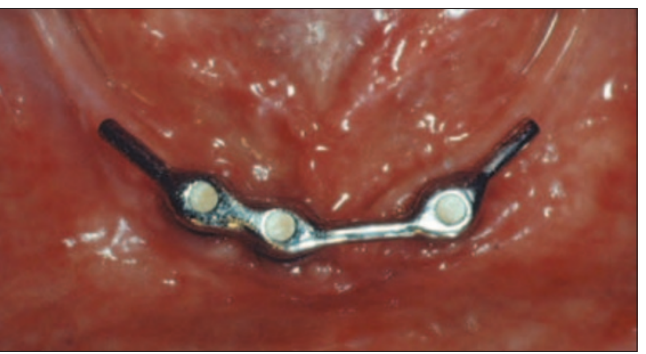

Costs for this type of restoration are higher than overdenture prostheses, however, the satisfaction of patients is also higher. Combined with fewer post operative visits for adjustments and un-scheduled appointments, the hybrid prosthesis becomes an attractive choice for treatment of edentulous patients, ${ }^{30,31}$ with the documentation available supporting the equivalent success of implants between the delayed and immediate loading protocols for providing this

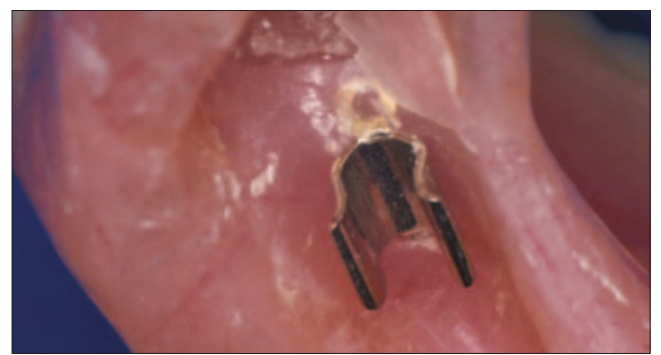
type of restoration. ${ }^{32-37}$ It is the authors' first choice to restore edentulous mandibles with hybrid prostheses using the immediate loading protocol (Fig. 25). Post operative visits are markedly reduced post insertion of the implants and provisional restoration and patient satisfaction and comfort are increased over conventional loading protocols. Even when providing overdenture prostheses to patients, care should be taken so that the implants placed for the overdenture prosthesis do not preclude placement of additional implants to support a hybrid type prosthesis.

Treatment planning for this type of restoration begins with a patient interview, followed by a clinical examination and a review of radiographs. A panoral radiograph is useful to determine the availability of bone to receive implants in the anterior mandible. A cross sectional film (CT scan or tomogram) of the area to receive implants is also useful to determine the bucco-lingual proportions of the bone. Alternatively the cross sectional dimensions of the bone can be mapped by sounding the bone. A minimum of 10-12 mm of inter occlusal space from the platform of the implant to the opposing occlusion is required for the implant components, framework and teeth. If insufficient space presents then consideration to increasing the vertical dimension, ostectomy or fixed metal ceramic restorations requiring less inter occlusal space must be considered.

A surgical guide is constructed based on the patient's existing complete denture or dentition if the teeth are in an acceptable position and implant surgery can proceed. Four to six implants are placed between the mental foramina in as exaggerated an arch form as possible - the more the anterior posterior spread the longer the cantilever can be made. ${ }^{37-39}$ In vitro and in vivo experiments have demonstrated that most stress is placed on the terminal implant 
when occlusal forces are applied to the cantilever. The two factors determine the length of the cantilever, the anterior posterior spread and the length of the terminal implant (Figs 26-27). This is also modified by what the opposing occluding arch is, ie a complete denture, natural dentition or implant supported restoration. Increased loading will demand a reduced length of cantilever. If too long a cantilever is placed, mechanical failure of the implant components of the prosthesis is a common sequela (Figs 28-29). To reduce the loading of the terminal implant some have advocated placing short implants distal to the mental foramina and having the cantilever segments rest on the implants without being connected. . $^{38-44}$

Once implants have been placed they can: 1) have cover screws placed and submerged under the mucosa (two stage); 2) have healing caps placed and have mucosa sutured around them (single stage); and 3) be immediately loaded. There are sufficient publications documenting the safety and efficacy of immediately loading implants that are splinted in the anterior mandible and this is the standard protocol of the authors. Resonance Frequency Analysis (RFA) measurements of implants placed in the anterior mandible indicate that the implants are stable on placement and continue to remain stable through osseointegration. Success rate studies have shown that the success of immediately loading implants in this location is similar to the delayed conventional protocol. The only modification made is that only short cantilevers are used on the provisional - usually only one premolar. ${ }^{45-46}$ With immediately loading the implants, a three to four month healing period and confirmation of osseointegration impressions can proceed for the definitive restoration. Alternatively if the patient is satisfied with the tooth position and function of the provisional restoration, analogues can be attached to the provisional restoration and set in a plaster cast, an index of the tooth positions can be made with putty silicone. At this time the cast can be mounted against the maxilla using the provisional restoration. Thus implant positions, jaw registration and tooth positions are established in one visit.

Under the buccal and lingual indices, framework construction can begin with care taken that there is sufficient room for teeth and acrylic resin. Attention must be paid to the dimensions of the framework - knowing that most stress is concentrated at the cantilever this area of the framework is made larger, an L beam shape is formed to maximise rigidity of the framework with large cavities for retention of the acrylic resin (Figs 30-33). Another approach to reduce mechanical failure and to allow an increased length of the cantilever is to place implants distal to the mental foramen: the prosthesis is not connected to these implants but merely rests on them, maintaining contact with healing caps on the implant (Fig. 34). This allows longer cantilevers and avoids the difficulty of passive fit across the arch and accommodates

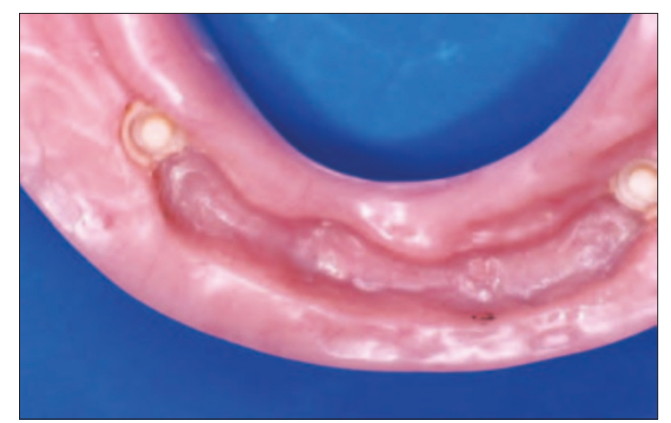

Fig. 19 Tissue surface of prosthesis made over tissue bar in Figure 18.

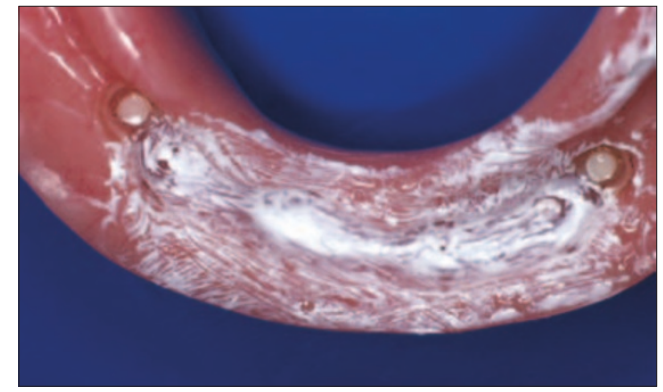

Fig. 20 The prosthesis in Figure 19 is adjusted to rotate freely with the help of disclosing paste.

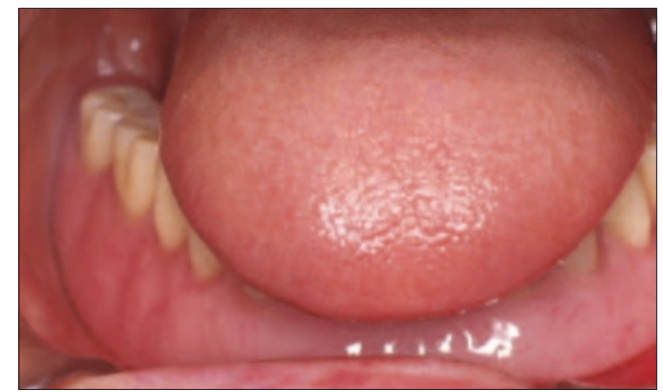

Fig. 21 The prosthesis for patient in Figure 18 inserted, it remains stable though the patient protrudes her tongue.

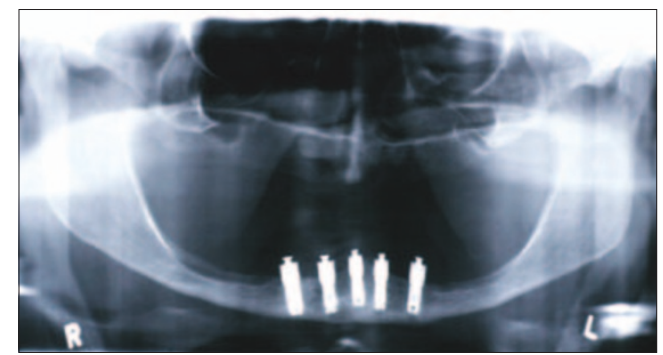

Fig. 22 Radiograph of implants placed in the anterior mandible to support a hybrid restoration.

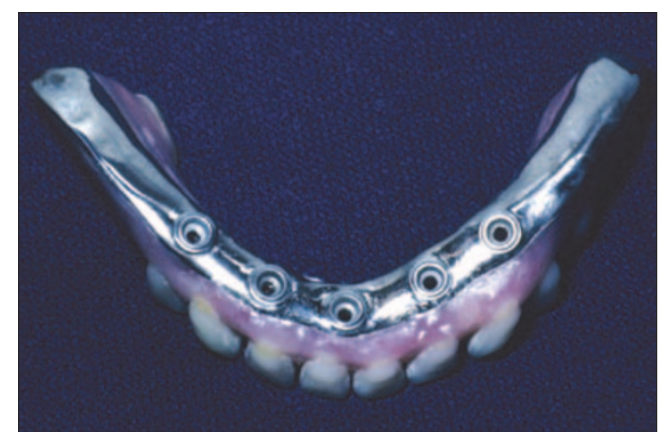

Fig. 23 Undersurface of a hybrid restoration illustrating the cantilever length that can be placed.

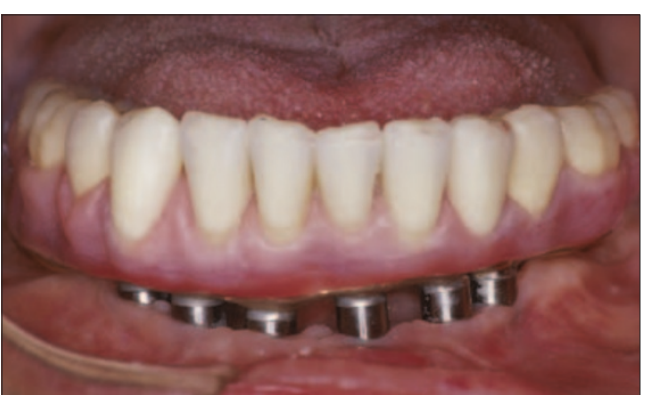

Fig. 24 Intra oral view of hybrid restoration illustrating full support of the restoration by implants alone without tissue contact. 
Fig. 25 Intra oral view of immediately placed provisional restoration. When hybrid restorations are placed for surfaces are always above the level of the mucosa to facilitate placement of the provisional restoration and minimal disturbance to the surgical site.

Fig. 26 The distribution of the cantilever. The length of the cantilever is equal to the length indicated in the diagram which is the antero-posterior spread of the implants. immediate loading, if possible the fit implants will dictate the length of
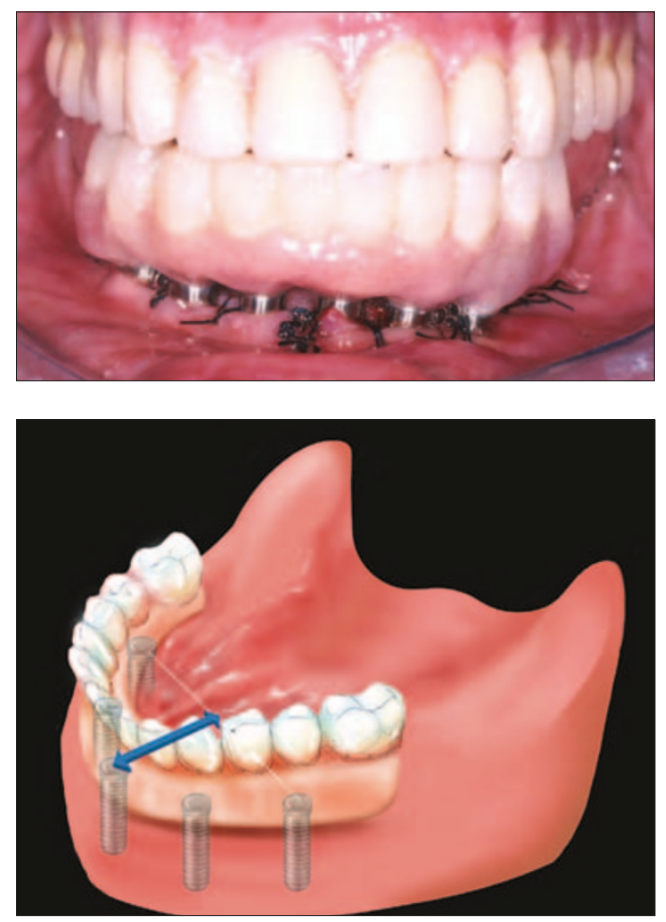

Figs 27a-27b Two master casts showing different a-p spreads and allowing different lengths of cantilever.

Fig. 28 Tissue surface of a hybrid prosthesis with poorly distributed implants and too large a cantilever.

Fig. 29 Implants supporting prosthesis in Figure 28; note the fractured screws in the anterior two implants caused by excessive loading due to cantilever length.
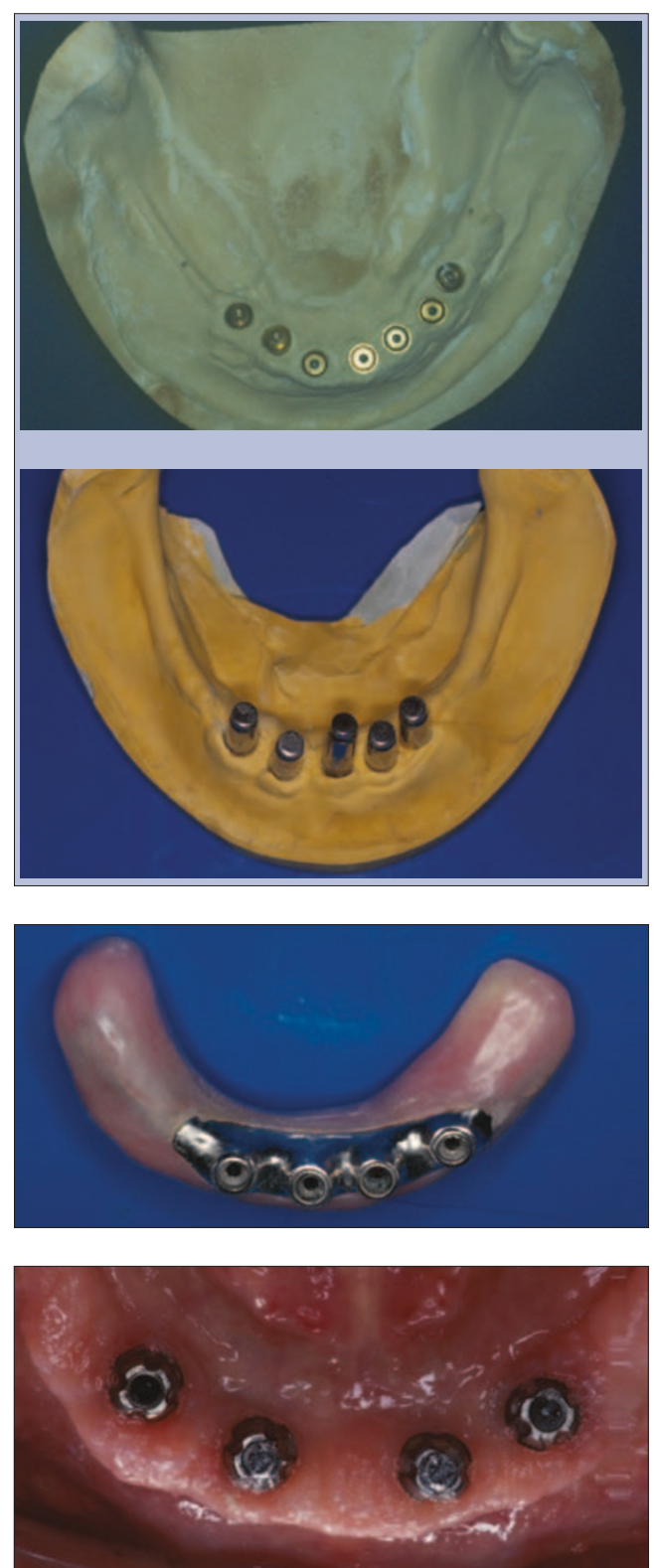

flexion of the mandible on opening and closing. The framework is tried in for passivity and acrylic resin and teeth are processed on the framework.

Framework materials range from gold alloys, silver palladium alloys to titanium. The gold and silver alloys are cast onto pre-machined cylinders and the titanium frameworks are milled by implant manufacturers. The authors' experience with these types of frameworks is that while they fit well, the relationship to the teeth and the contours are not considered carefully in fabricating the frameworks - often leading to awkward contours of the finished prostheses. Certainly this will improve with time and experience as some method of interaction is developed between the clinician and the machinist for the frameworks (Fig. 35).

\section{METAL CERAMIC FIXED UNITS}

When patients present while dentate with many of the teeth unrestorable, for periodontal or structural reasons there are times when removing these teeth in order to provide implant supported restorations becomes the most common option. As the alveolar housing is still present as teeth are retained, the minimal resorption would contraindicate the use of a hybrid prostheses. In these situations all the principles of restoring teeth in the anterior and posterior quadrants which have been described in earlier articles must apply.

For this type of restoration more implants are required to support the restoration for both biomechanical, technical and ease of maintenance issues. The bulk of the frameworks are smaller therefore cantilevers should be avoided, metal ceramic units distort during fabrication so short segments are easier to manage and repairs and maintenance are easier with short spans.

Another reason why more implants and full arch restorations should be avoided is mandibular flexion. Many reports have addressed the $t$ dimensional changes of the mandible during jaw activity as a result of masticatory muscle action. ${ }^{47}$ The theoretical implications argue against one piece full arch restorations. Considerable buccolingual forces on opening and closing will be applied to the restoration and the restoration abutment interface.

The treatment planning guidelines are similar to what was discussed for the edentulous maxilla. The following parameters need to be evaluated.

1. Aesthetics - As patients get older the display of the mandibular anterior teeth increases. Aesthetics in this regard is appropriate placement of the mandibular central incisor and display of teeth in speech and smiling.

2. Interarch space - The interarch space requires 6-8 $\mathrm{mm}$ from the head of the implant to the opposing occlusion. This allows appropriate tooth length and accommodation of vertical and horizontal overlap.

3. Number and distribution of implants - Deciding on the number of implants to place is not 
governed by a formula and is dependent on multiple factors. The number of implants to place in each patient is determined by:

1. Quality of bone

2. Anticipated force to be placed on the restoration

3. The segmentation of the units.

Usually three segments are fabricated, one replacing each posterior sextant and one anteriorly. Force estimations for each segment should be assessed based on the factors outlined above and the number of implants determined accordingly.

With this type of restoration the implant position is more critical than the other two choices of restoration, therefore the surgical guide and stabilisation of the surgical guide is critical. At times teeth can be maintained to help and if this is not possible, temporary implants can be used to aid in stabilising surgical guides. ${ }^{48}$

Figures 36 to 39 illustrate an edentulous mandible restored with metal ceramic restorations, this patient was recently edentulate and presented with minimal bone resorption. Implants were placed using temporary implants to stabilise the surgical guide and following this the implants were immediately loaded with a provisional restoration. After confirmation of integration the definitive metal ceramic restorations were delivered.

\section{CONCLUSION}

There are three main choices for restoring the mandibular arch with implants: a minimalist approach with two implants to retain a removable prosthesis or a fixed restoration which may be a hybrid type restoration or metal ceramic implant supported restoration. The overdenture type restoration is the least expensive initially, however, it requires more maintenance and the prosthesis continues to load tissues posterior to the implants.

The fixed types of prostheses will provide almost normal function and require minimal post operative adjustments; the overdenture is more economical and very satisfactory for those patients who lack the muscular coordination to wear complete dentures but have no complaint of pain due to loading of the mucosa.

The choice between the hybrid and metal ceramic restorations essentially depend on the amount of bone loss that patients present with; secondarily the cost of the metal ceramic units together with the increased number of implants may determine the type of restoration provided. Patients should be made aware that acrylic teeth on a hybrid type restoration may need to be replaced five to six years following delivery and this may have additional financial repercussions. Similarly porcelain fracture is possible on the metal ceramic units.

Patient satisfaction and function are higher with the fixed options; the advantages and disadvantages of each must be discussed with patients prior to initiation of treatment.

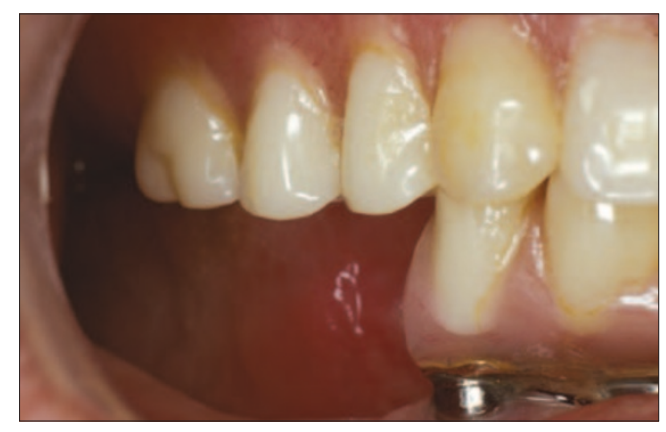

Fig. 30 Intra oral view of fractured hybrid restoration.

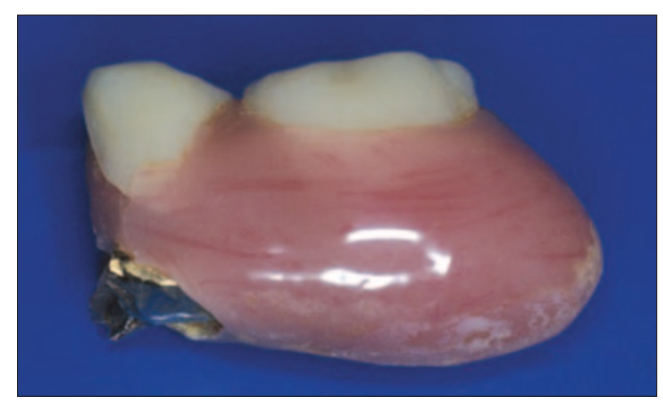

Fig. 31 Fractured fragment from Figure 30.

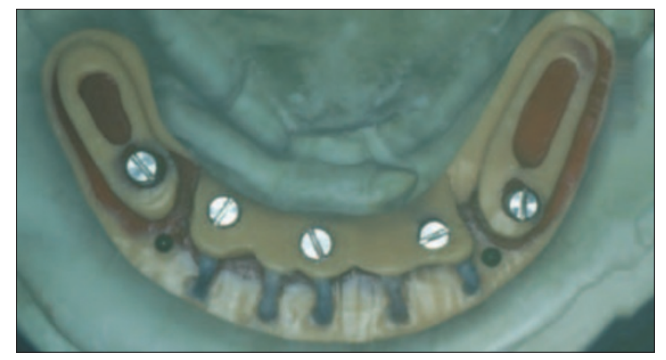

Fig. 32 Framework design

illustrating acrylic retentive areas and dimensions required to resist fracture.

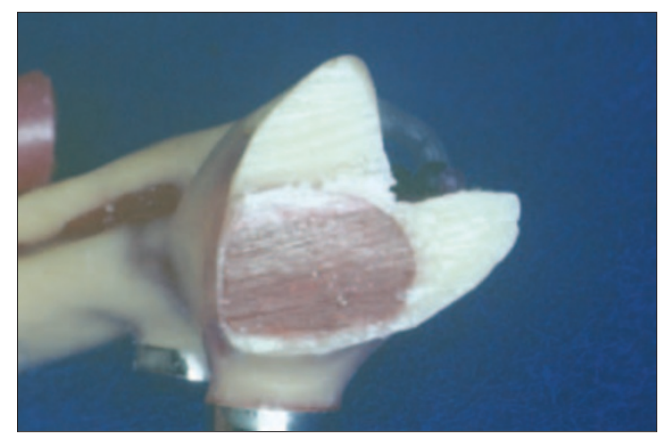

Fig. $33 \mathrm{~L}$ shaped cross section of the framework to resist occlusal forces yet allow space for acrylic resin.

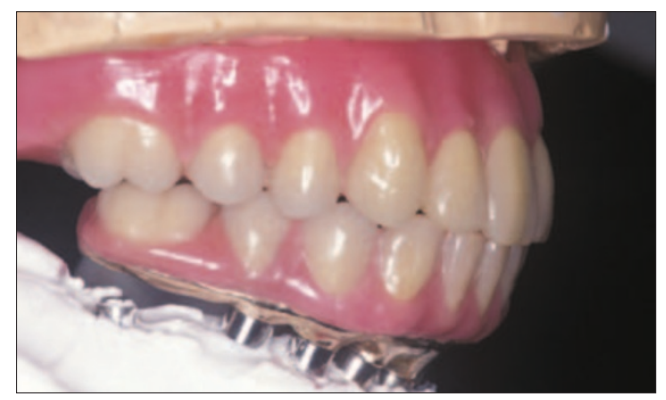

Fig. 34 Lateral view of maxillary denture and mandibular hybrid restoration on articulator. Note implant positioned below cantilever extension, a healing cap will be placed to make contact with the undersurface of the prosthesis intra orally.

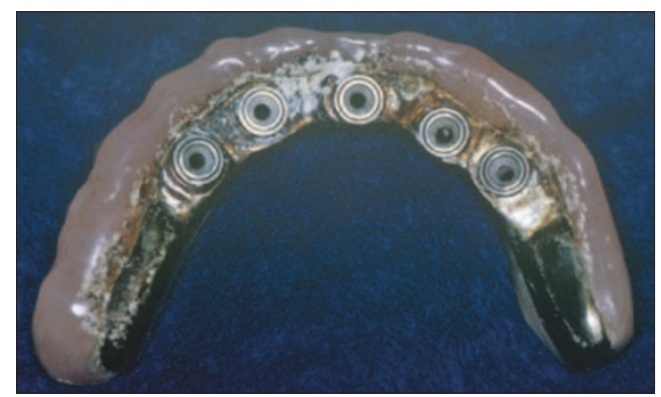

Fig. 35 Poor contours of titanium frameworks resulting in ridge lap of acrylic and poor oral hygiene. 
Fig. 36 Eight implants have been placed in this patient using a surgical guide indexed on the teeth. The strategic abutments have been maintained to support a fixed provisional restoration whilst the implants integrate.

Fig. 37 Occlusal view showing ideal implant placement for screw retained restorations. Note the temporary implants in the posterior where the surgical guide was indexed.

Fig. 38 Well controlled implant placement resulting in ideal implant positions for screw retention. This restoration was segmented distal to the left and right canines.

Fig. 39 Anterior view of restoration, note minimal space available for restorations resulting in choice of metal ceramic restorations to replace teeth in the mandibular arch.

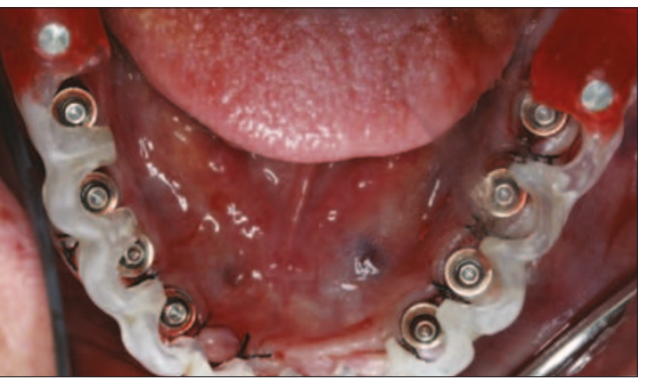

evaluation of implant treatment in edentulous patientspreliminary results. Int J Prosthodont 2005; 18: 20-27.

9. Takanashi Y, Penrod J R, Lund J P, Feine JS. A cost comparison of mandibular two-implant overdenture and conventional denture treatment. Int J Prosthodont 2004; 17: 181-186.

10. Thomason J M, Lund J P, Chehade A, Feine J S. Patient satisfaction with mandibular implant overdentures and conventional dentures six months after delivery. Int J Prosthodont 2003; 16: 467-473.

11. Awad M A, Lund J P, Shapiro S H et al. Oral health status and treatment satisfaction with mandibular implant overdentures and conventional dentures: a randomized clinical trial in a senior population. Int J Prosthodont 2003; 16:390-396

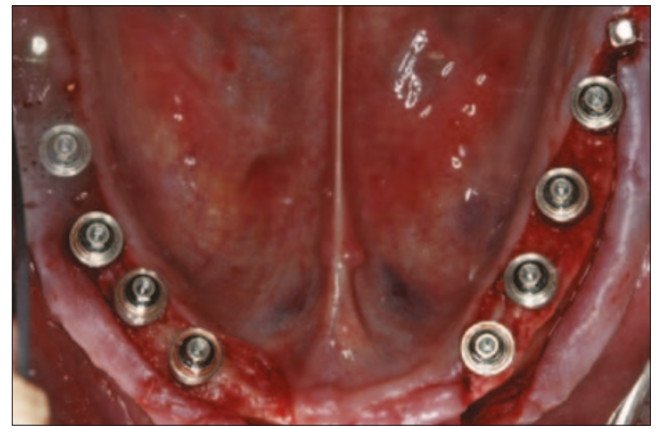

12. Melas F, Marcenes W, Wright P. Oral health impact on daily performance in patients with implant-stabilized overdentures and patients with conventional complete dentures. Int J Oral Maxillofac Implants 2001; 16: 700-712.

13. Heydecke G, Locker D, Awad M A et al. Oral and general health-related quality of life with conventional and implant dentures. Comm Dent Oral Epidemio/ 2003; 31: 161-168.

14. Awad M A, Lund J P, Dufresne E, Feine J S. Comparing the efficacy of mandibular implant-retained overdentures and conventional dentures among middle-aged edentulous patients: satisfaction and functional assessment. Int J Prosthodont 2003; 16: 117-122.

15. Morais J A, Heydecke G, Pawliuk J et al. The effects of mandibular two-implant overdentures on nutrition in elderly edentulous individuals. J Dent Res 2003; 82: 53-58.

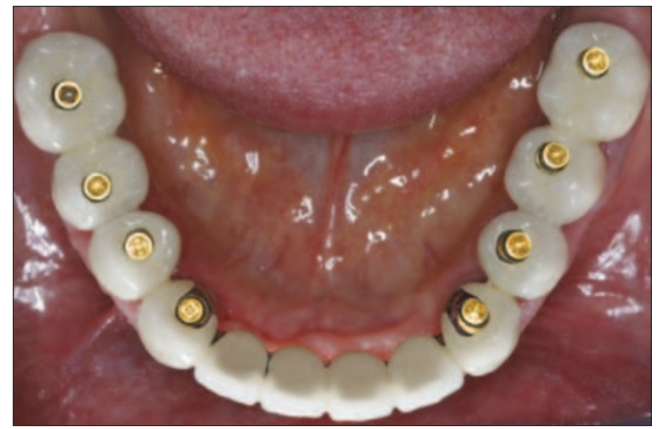

16. Attard N J Zarb G A Long-term treatment outcomes in edentulous patients with implant overdentures: the Toronto study. Int J Prosthodont 2004; 17: 425-433.

17. Chaffee N R, Felton D A, Cooper L F et al. Prosthetic complications in an implant-retained mandibular overdenture population: initial analysis of a prospective study. J Prosthet Dent 2002; 87: 40-44.

18. Payne A G, Walton T R, Walton J N, Solomons Y F. The outcome of implant overdentures from a prosthodontic perspective: proposal for a classification protocol. Int J Prosthodont 2001; 14: 27-32.

19. Walton J N, MacEntee M I. Problems with prostheses on implants: a retrospective study. J Prosthet Dent 1994 71: 283-288.

20. Payne A G, Solomons Y F. Mandibular implant-supported overdentures: a prospective evaluation of the burden of prosthodontic maintenance with three different attachment systems. Int J Prosthodont 2000: 13: 246-253

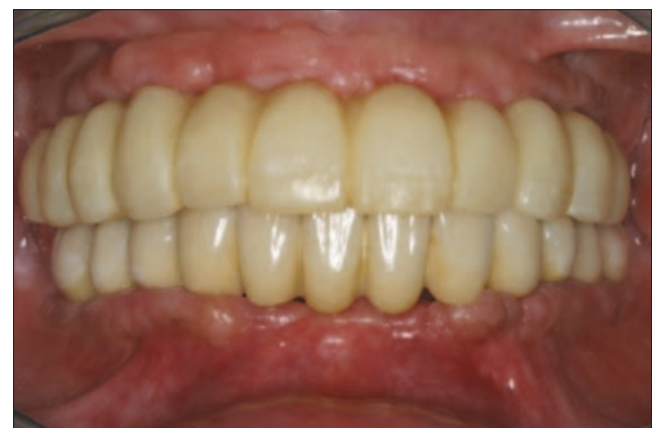

1. Zarb G A. The edentulous milieu. J Prosthet Dent 1983; 49: 825-831.

2. Zitzmann N U, Marinello CP. A review of clinical and technical considerations for fixed and removable implant prostheses in the edentulous mandible. Int J Prosthodont 2002; 15: 65-72.

3. Feine J S, Carlsson G E, Awad M A et al. The McGill consensus statement on overdentures. Mandibular two-implant overdentures as first choice standard of care for edentulous patients. Gerodontology 2002; 19: 3-4.

4. Gotfredsen $\mathrm{K}$, Holm B. Implant-supported mandibular overdentures retained with ball or bar attachments: a randomized prospective 5-year study. Int J Prosthodont 2000: 13: 125-130.

5. Cordioli G, Majzoub Z, Castagna S. Mandibular overdentures anchored to single implants: a five-year prospective study. JProsthet Dent 1997: 78: 159-165.

6. Naert I, Gizani S, Vuylsteke M, van Steenberghe D. A 5-year randomized clinical trial on the influence of splinted and unsplinted oral implants in the mandibular overdenture therapy. Part I: Peri-implant outcome. Clin Oral Implants Res 1998; 9: 170-177.

7. Chee W W. Considerations for implant overdentures. J CalifDent Assoc 1992: 20: 25-28.

8. Zitzmann N U, Sendi P, Marinello C P. An economic
1. Attard N J, Zarb G A, Laporte A. Long-term treatment costs associated with implant-supported mandibular prostheses in edentulous patients. Int J Prosthodont 2005; 18: 117-123.

22. Thiel $C P$, Evans $D B$, Burnett R R. Combination syndrome associated with a mandibular implant-supported overdenture: a clinical report. J Prosthet Dent 1996; 75: 107-113.

23. Lechner S K, Mammen A. Combination syndrome in relation to osseointegrated implant-supported overdentures: a survey. Int J Prosthodont 1996: 9: 58-64.

24. Jacobs R, Schotte A, van Steenberghe D et al. Posterior jaw bone resorption in osseointegrated implant- supported overdentures. Clin Oral Impl Res 1992; 3: 63-70.

25. Narhi T O, Geertman M E, Hevinga M et al. Changes in the edentulous maxilla in persons wearing implant-retained mandibular overdentures. J Prosthet Dent 2000; 84: 43-49.

26. Chiapasco M, Gatti C. Implant-retained mandibular overdentures with immediate loading: a 3- to 8-year prospective study on 328 implants. Clin Implant Dent Relat Res 2003; 5: 29-38.

27. Payne A G, Tawse-Smith A, Thompson W M, Kumara R. Early functional loading of unsplinted roughened surface implants with mandibular overdentures 2 weeks after surgery. Clin Implant Dent Relat Res 2003; 5: 143-153.

28. Adell R, Eriksson B, Lekholm U et al. Long-term follow-up study of osseointegrated implants in the treatment of totally edentulous jaws. Int J Oral Maxillofac Implants 1990; 5: 347-359.

29. Ferrigno N, Laureti M, Fanali S, Grippaudo G. A long-term follow-up study of non-submerged ITI implants in the treatment of totally edentulous jaws. Part I: Ten-year life table analysis of a prospective multicenter study with 1286 implants. Clin Oral Implants Res 2002; 13: $260-273$

30. Attard N J, Zarb G A. Long-term treatment outcomes in edentulous patients with implant-fixed prostheses: the Toronto study. Int J Prosthodont 2004; 17: 417-424. 
31. Zitzmann N U, Sendi P, Marinello C P. An economic evaluation of implant treatment in edentulous patientspreliminary results. Int J Prosthodont 2005; 18: 20-27.

32. Becker W, Becker B E, Huffstetlert S. Early functional loading at 5 days for Branemark implants placed into edentulous mandibles: a prospective, open-ended, longitudinal study. J Periodontol 2003; 74: 695-702.

33. Schnitman PA, Wohrle PS, Rubenstein J E et al. Ten-year results for Branemark implants immediately loaded with fixed prostheses at implant placement. Int J Oral Maxillofac Implants 1997; 12: 495-503.

34. Balshi T J, Wolfinger $\mathrm{G} \mathrm{J}$. Immediate loading of Branemark implants in edentulous mandibles: a preliminary report. Implant Dent 1997

35. Chee W, Jivraj S. Efficiency of immediately loaded mandibular full-arch implant restorations. Clin Implant Dent Relat Res 2003; 5: 52-56.

36. Tarnow D P, Emtiaz S, Classi A. Immediate loading of threaded implants at stage 1 surgery in edentulous arches: ten consecutive case reports with 1- to 5-year data. Int J Oral Maxillofac Implants 1997; 12: 319-324.

37. Randow K, Ericsson I, Nilner K et al. Immediate functional loading of Branemark dental implants. An 18-month clinical follow-up study. Clin Oral Implants Res 1999; 10: 8-15.

38. English C E. Critical A-P spread. Implant Soc 1990; 1:2-3.

39. McAlarney M E, Stavropoulos D N. Theoretical cantilever lengths versus clinical variables in fifty-five clinical cases. J Prosthet Dent 2000; 83: 332-343.

40. McAlarney M E, Stavropoulos D N. Determination of cantilever length-anterior-posterior spread ratio assuming failure criteria to be the compromise of the prosthesis retaining screw-prosthesis joint. Int J Oral Maxillofac Implants 1996; 11:331-339.

41. White S N, Caputo A A, Anderkvist T. Effect of cantilever length on stress transfer by implant-supported prostheses. JProsthet Dent 1994; 71: 493-499.

42. Rodriguez A M, Aquilino S A, Lund PS et al. Evaluation of strain at the terminal abutment site of a fixed mandibular implant prosthesis during cantilever loading. J Prosthodont 1993; 2: 93-102.

43. McCartney J W. Cantilever rests: an alternative to the unsupported distal cantilever of osseointegrated implantsupported prostheses for the edentulous mandible. J Prosthet Dent 1992; 68: 817-819.

44. Jemt $T$, Carlsson L, Boss A, Jorneus L. In vivo load measurements on osseointegrated implants supporting fixed or removable prostheses: a comparative pilot study. Int J Oral Maxillofac Implants 1991; 6: 413-417.

45. Bischof M, Nedir R, Szmukler-Moncler S et al. Implant stability measurement of delayed and immediately loaded implants during healing. Clin Oral Implants Res 2004; 15: 529-539.

46. Barewal R M, Oates T W, Meredith N, Cochran D L.

Resonance frequency measurement of implant stability in vivo on implants with a sandblasted and acid-etched surface. Int J Oral Maxillofac Implants 2003; 18: 641-651.

47. Goodkind R J, Heringlake C B. Mandibular flexure in opening and closing movement. J Prosthet Dent 1972; 30: 134-138.

48. Aalam A A, Reshad M, Chee W W, Nowzari H. Surgical template stabilization with transitional implants in the treatment of the edentulous mandible: a technical note. Int J Oral Maxillofac Implants 2005; 20: 462-465. 